\title{
PRODUCTION AND APPLICATIONS OF BACTERIOCINS FROM LACTIC ACID BACTERIA
}

\section{SUHAGIYA S AND SHRIVASTAV A*}

Department of Microbiology, Parul Institute of Applied Sciences, Parul University, Vadodara 391760, Gujarat, India

*Corresponding Author: E Mail: Anupama.shrivastav82045@paruluniversity.ac.in Received $10^{\text {th }}$ March 2021; Revised $8^{\text {th }}$ April 2021; Accepted $10^{\text {th }}$ May 2021; Available online $1^{\text {st }} \mathrm{Jan}^{2022}$

\section{https://doi.org/10.31032/IJBPAS/2022/11.1.5825}

\section{ABSTRACT}

Lactic acid bacteria show antimicrobial activity in the fermented food, due to production of compound like bacteriocins, various metabolites, including lactic acid, hydrogen peroxide and non-fermented foods, high diversity of many bacteriocins are produced by lactic acid bacteria. Numerous bacteriocins are characterized chemically, biochemically and genetically. Lactic acid bacteria are used from centuries for fermentation in food and they are inhibitory for many other organisms. In laboratory fermentation, it has been studied that bacteriocin which is produced in starter culture is to increase the competitiveness, to show anti-listerial and anti-clostridial effect in cheddar cheese and fermented sausage. It plays important role in food safety and its quality. Bacteriocins are ribosomally synthesized antimicrobial peptides/proteinaceous compounds produced by bacterial strains including many Gram-positive species. Bacteriocin is actually a proteinaceous toxin that is created as a tiny molecule by bacteria. Bacteriocin productions from lactic acid bacteria have been studied in recent year and a numbers have been described.

\section{Keywords: Bacteriocins, Lactic Acid Bacteria, Fermentation, Proboitics, Antimicrobial Activity}

\section{INTRODUCTION}

Lactic acid bacteria are having gram positive nature, they are non-spore formers and having rod / cocci shape and are aero tolerant. Lactic acid bacteria are also fastidious organisms. They have ability to ferment carbohydrate into energy and lactic acid. Lactic acid bacteria shows 
antimicrobial activity in the fermented food, due to production of compound like bacteriocins, various metabolites, including lactic acid, hydrogen peroxide and some organic acids [3]. Lactic acid bacteria are characterized by the production of lactic acid as a main product from growth inhibition substance like bacteriocins, and hydrogen peroxide etc. And on other hand glucose, which will prevent the growth of pathogens and food spoilage bacteria. If the lactic acid bacteria are isolated by homemade fermented vegetables it produces antimicrobial substance against both gram positive and gram negative, common food borne bacterial pathogens.

\section{WHAT ARE BACTERIOCINS?}

Bacteriocins are unit proteins or germicidal peptides that are active against species closely associated with the manufacturing organism [1]. Bacteriocins are a sort of supermolecule that is created by bacterium. Bacteriocins have tendency to penetrate the outer membrane of gram negative bacterium that is created from carboxylic acid bacterium. Bacteriocin also inhibits the expansion of different microorganisms. Bacteriocin such as nisin is just a bacteriocin that is wide used for food preservative [4]. The only bacteriocin to search out application within the food industry till date is nisin. Nisin is formed by sure strains of lactococcus lactis. Bacteriocins are ribosomally-synthesized peptides therefore may be bioengineered at specific web site or residue to form them effective against the food- spoilage against bacterium. Bacteriocins are created by one bacterium are able to repress different bacterium that belong to same species. Many bacteriocins having potential industrial application has been characterized and isolated. Several of the bacteriocins may be able to preserve food once the falterating of cold chain whereas heat sensitive food is transit, though only Nisin and Pediocin have approved by the Food and Drug Administration (FDA) [5]. Bacteriocins manufacturing strains can defend themselves from unfriendly action of their own bacteriocins by manufacturing specific immunity supermolecule. Cistron that encodes this supermolecule has shut genetic proximity to different bacteriocins and process genes. The accent proteins are organized in deoxyribonucleic acid clusters that reside either in order, different mobile genetic parts or plasmids. This deoxyribonucleic acid is inducible in living thing accumulation of peptides for indication and in the main needs secretion. The antimicrobial activity was sustained between eighteen to twenty four hours 
within the bacteriocin. From the hard meat the carboxylic acid bacterium was isolated that is a great source supply of novel bacteriocins [2].

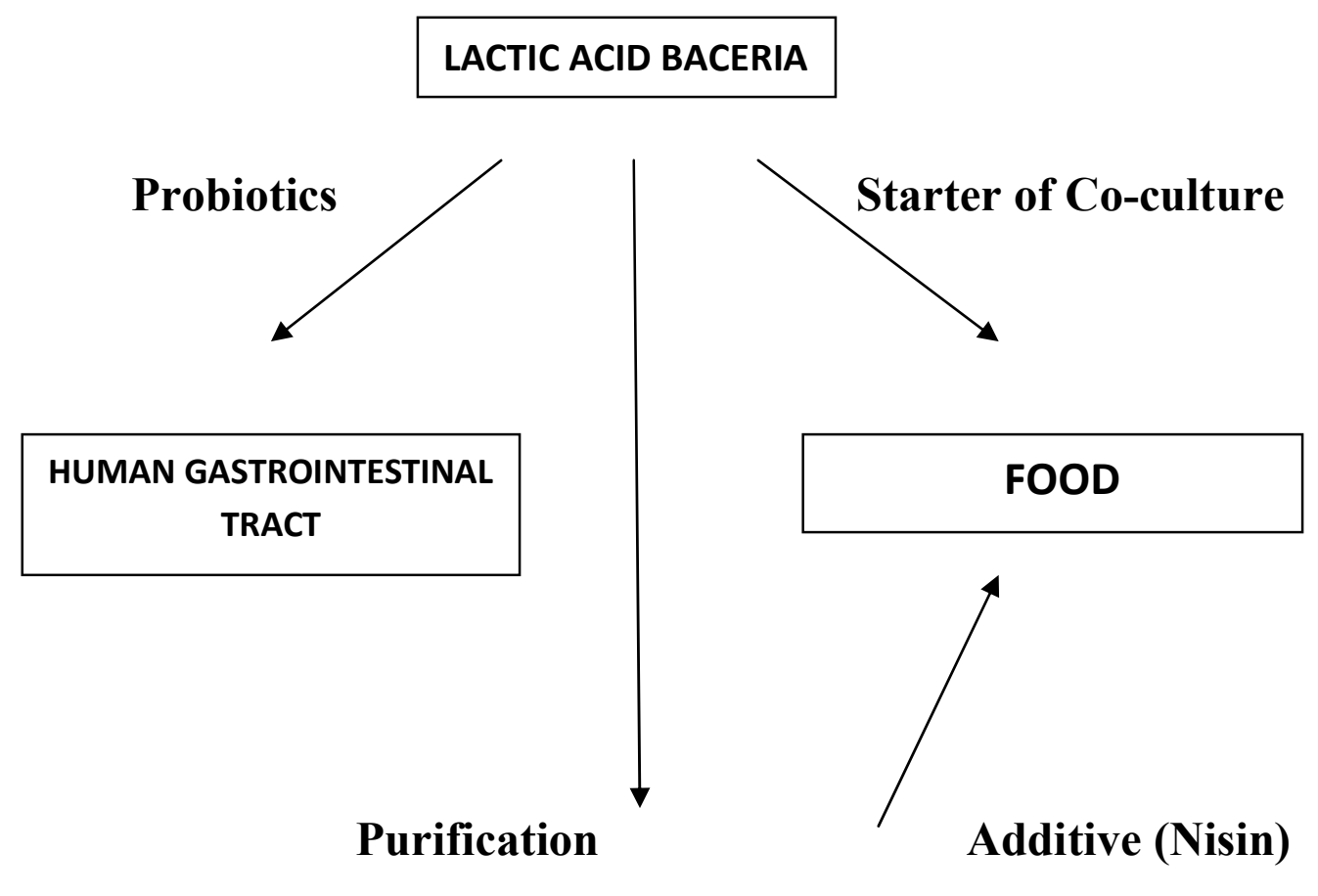

CLASSIFICATION OF BACTERIOCINS

Bacteriocins are produced by both gram positive and gram negative species. Bacteriocins are classified on the bases of their primary structure, molecular weight, genetic characteristics and post transitional mechanisms. They are classified in four groups:
Class I - Bacteriocins

Class II - Bacteriocins

Class III - Bacteriocins

Class IV - Bacteriocins 
Table 1: The following table illustrates the type of lactic acid bacteria producing bacteriocins, the method through which it is producing bacteriocins with the properties and example of bacteriocins

\begin{tabular}{|c|c|c|c|c|}
\hline Class & Producing strains & Description & Properties & Example \\
\hline I (lantibiotics) & $\begin{array}{l}\text { Lactobacillus lactis } \\
\text { subsp. Lactis }\end{array}$ & $\begin{array}{c}\text { Post- } \\
\text { transitionally } \\
\text { modified } \\
\text { bacteriocins }\end{array}$ & $\begin{array}{l}\text { Contains unique amino acid, } \\
\text { i.e. lanthionine, } \\
\text { methyllanthionine }(<5 \mathrm{kDa}) \\
\text { and dehydrated residues }\end{array}$ & $\begin{array}{c}\text { Nisin A } \\
\text { Lacticin3147 } \\
\text { Suicin } 3908[2,18]\end{array}$ \\
\hline IIa & Leuconostoc gelidum & $\begin{array}{l}\text { Unmodified } \\
\text { peptide }\end{array}$ & $\begin{array}{l}\text { Contains double glycine } \\
\text { leader peptide, small, heat } \\
\text { stable, hydrophobic peptide } \\
\text { and active peptide (<10kDa) }\end{array}$ & $\begin{array}{c}\text { Pediocin PA-1 } \\
\text { Sakicin A } \\
\text { Leucocin A [2,17] }\end{array}$ \\
\hline IIb & Enterococcus fecium & $\begin{array}{l}\text { Unmodified } \\
\text { peptide }\end{array}$ & $\begin{array}{l}\text { Mostly cationic peptide. } \\
\text { Requires synergy of two } \\
\text { complementary peptide }\end{array}$ & $\begin{array}{l}\text { Aureocin A53 } \\
\text { Plantariocin A } \\
\text { Entercin X [5] }\end{array}$ \\
\hline IIc & $\begin{array}{c}\text { Lactobacillus } \\
\text { acidophilus }\end{array}$ & $\begin{array}{l}\text { Unmodified } \\
\text { peptide }\end{array}$ & $\begin{array}{c}\text { Affect membrane } \\
\text { permeability and cell wall } \\
\text { formation }\end{array}$ & $\begin{array}{l}\text { Lactococcin G } \\
\text { Reuterin [6] }\end{array}$ \\
\hline III & $\begin{array}{c}\text { Lactobacillus } \\
\text { helveticus }\end{array}$ & $\begin{array}{l}\text { Unmodified } \\
\text { peptide }\end{array}$ & $\begin{array}{c}\text { Large heat( }>30 \mathrm{kDa}), \text { large } \\
\text { molecular mass peptide, } \\
\text { labile protein }\end{array}$ & $\begin{array}{c}\text { Lysostaphin } \\
\text { Enterolysin A } \\
\text { Helveticin J }\end{array}$ \\
\hline
\end{tabular}

\section{PRODUCTION OF BACTERIOCINS}

During the fermentation bacteriocins are found in the food matrix, bacteriocins which are produced by lactic acid bacteria can be produced in much higher amount during in vitro fermentation under optimal physical and chemical conditions [6]. Bacteriocin production is depended on the microbial strains and cultures. Bacteriocins are ribosomally synthesized peptides, which are biologically inactive and later they are modified to attain active state that include on N-terminal leader peptide attached to Cterminal pro-peptide. The leader peptide: -

1) Serves as a recognition site which directs the pre-peptides towards maturation and transport protein.

2) Protect the producer strains by keeping the bacteriocin in inactive state while it is inside the producer strain.

3) Interact with the pro-peptides domain to ensure it is in a suitable conformation for enzyme-substrate interaction of the modification machinery.

Bacteriocins production is very commonly found among the bacteria. It was found that bacteriocins are produced by almost all the bacteria. This is because their biosynthetic machinery is relatively simple and is often associated with transferable elements such as conjugative transposones/plasmids [20]. Newly synthesized bacteriocins contains Nterminals which are then modified by proteins/amino acid encoded by the bacteriocins gene cluster before they are exported out of the cell. The gene which encodes bacteria production and immunity 
are organized in operon cluster which can be located on mobile genetic elements. Due to absence of limiting factor, like a strong diffusion limitation, inactivation by proteases and food particles adsorption there is high in vitro production [21]. Whenever during controlling of fermented experiments some considerable differences are obtained to yield activity and influence of the environmental conditions also affect the bacteriocin activity. For instance, a decrease of $\mathrm{pH}$ results in a decreased adsorption of the bacteriocin molecules to the procedure cells, and hence in an increased bioavailability [22]. In the synthesis of bacteriocins $\mathrm{pH}$, temperature and nutrient availability play a major part. Lantibiotic biosynthesis begins with translating of the pre-peptide, which consists of a leader peptide and a modifiable propeptide moiety. The pre-peptide then undergoes modification, following which the modified pre-peptide translocated across the cytoplasm membrane and the leader peptide is cleaved proteolytically by specific enzymes. Bacteriocins protect themselves from the intolerance action of their own bacteriocin by producing specific immunity protein. Genes encoding these proteins are in close genetic proximity to other bacteriocin structural and processing genes [14]. Lactobacillus helveticus LP27 which produces bacteriocin designated as lactocin 27 , possess a narrow spectrum of inhibition which affects only strains of L.acidophilus and L. lactocin 27 [11]. From culture supernatants it was isolated as a protein lipopolysaccharide complex with a molecular weight of 200000. The bacteriocin can be inactivated by trypsin and pronase, but not by ficin. It is extremely heat stable. Lactocin 27 can absorb equally to both sensitive and resistant bacteria cells and exhibites a bacteriostatic effect on the indicator strain, Lactobacillus helveticus LS18 [24]. Lactocin 27 can terminate protein synthesis, but DNA and RNA synthesis and ATP levels are not affected. The pediococci are important in a variety of vegetable fermentations where they play a major role in acid production, flavor development and the succession of microorganisms in natural fermenting ecosystems. In 1966, study reported that growth of plantarum was severely retarded in brined cucumber fermentations when the inoculum included strain FBB-61 of $P$. cerevisiae [25]. It was suggested that some factor, other than acid production, was responsible for the antagonistic activity of the Pediococcus culture. Later, compared the inhibitory activities of 16 different Pediococcus cultures against bacteria and yeasts associated with the fermentation of 
brined cucumbers. Two $P$. cerevisiae strains, FBB-61 and L-7230, consistently inhibited growth of gram-positive bacteria including other pediococci, L. plantarum, Micrococcus luteus, Streptococcus faecalis, Streptococcus aureus and etc. The two inhibitory strains of pediococci do not demonstrate antagonistic effects against each other, gram-negative bacteria or yeasts. The general effectiveness of the inhibitor against Lactobacillus Plantarum and other gram positive bacteria is highly significant considering that both competitive and pathogenic types are inhibited. Fleming et al. has suggested that the production of the inhibitor might explain the appearance during the first stages of natural fermentations of salt solution dipped cucumbers and Spanish type green olives by pediococci. Study examined $P$. pentosaceus Bacteriocin strains FBB-61 and L-7230 for plasmid content and genetic stability of bacteriocin production and host cell immunity [10]. P. pentosaceus FBB-61 was propagated at $42^{\circ} \mathrm{C}$ in a glucose-limited chemo stat operating at a dilution rate of 0.2 . After 14 days in chemostat culture, $53 \%$ of the colonies were negative bacteriocins. Loss of bacteriocin generation was done by loss of host cell immunity, denoting that the phenotypes were closely linked on an unstable genetic determinant. Plasmid analysis of $P$. pentosaceus FBB-61 identified a 13.6 MDa plasmid which was absent from each of the variants of FBB-61 analyzed. The second producer strain, L-7230, harbored a similar 13.6 MDa plasmid, but variants ofL7230 could not be isolated. Limited restriction analysis provided evidence that the 13.6 MDa plasmids in both strains were similar and suggested that pMD136 also encodes production of the bacteriocin in $P$. pentosaceus L-7230. Plasmid-borne considerations for inhibitor production and host cell immunity in $P$. pentosaceus FBB-61 provided genetic evidence supporting involvement which was designated pediocin A. Daeschel and Klaen hammer extended the survey of Fleming et al [19] and found that pediocin $A$ is active against additional pediococci, Clostridium botulinum, Clostridium sporogene, S. aureus, L. brevis and the nisin producer, S. lactis. It is highly significant that the inhibitory action of Pediocin A includes Gram-positive bacteria commonly incriminated in food-borne outbreaks. More recent work has demonstrated that Pediocin $\mathrm{A}$ is also effective against pathogenic Listeria monocyte genes. The effectiveness of pediocin A against food-borne microorganisms of public health significance warrants additional efforts to develop novel 
food-preservative systems and starter cultures for food fermentations. As noted earlier, application of genetic technologies might generate starter cultures of lactic acid bacteria that produce pediocin A [10]. Improved competition by starter cultures inoculated into natural fermentation systems and improved control of food-borne pathogens associated with fermented foods are exciting developments that can be anticipated with the development and use of cultures producing pediocins or similar bacteriocins with broad activity spectra. Bacteriocins production from poultry industries has become an important source of economic benefits in numerous countries [19]. There are two major pathogens in the poultry industry which have been studied in the aspect that has focused on E. coli. It is a gram-negative bacterium that is a normal member of gastrointestinal microflora in poultry. This strain can cause severe diseases. Systematic infection develops when large numbers of pathogenic E. coli gain access to the bloodstream from the respiratory or intestinal tract [11]. In the study screened LAB isolated from the intestinal sample and had founded two isolated strains (lactobacillus fermentum and lactobacillus rhanmnous) with the tendency to inhibit the growth of E. coli in vitro [13].
Numerous studies have implicated bacteriocins as participants in the antimicrobial activities displayed by $L$. acidophilus [12, 17]. However, a majority of these suspected antagonists have not been characterized sufficiently to determine whether or not bacteriocins are involved. Studies described bacteriocins - like inhibitor produced in liver agar cultures by $L$. acidophilus. 'Lactocidin' is non-volatile, insensitive within dialysis membranes [17]. Both Gram-positive and Gram-negative genera are restricted by $L$. acidophilus cultures implicated in lactocidin production. This wide spectrum of antagonistic activity prompted to suggest that L. acidophilus may control the proliferation of undesirable micro flora in the intestinal tract animals [17]. Further information which characterizes lactose in or identifies other bacteriocins which inhibit both Gram-positive and Gramnegative bacteria has not appeared. In this regard, bacteriocins of Lactobacillus acidophilus which are generally isolated and do not show inhibitory effects on Grampositive and Gram-negative bacteria and generally antagonize only closely related species within the Lactobacillaceae family. A protein of 5000-6000 $\mathrm{Da}$ is obtained on the purification of lactacin $B$ which can be inhibited by Proteinase $\mathrm{K}$ but remain active 
with 0.1 Urea concentration [18]. Advantageous effects of lactobacilli in dietary supplements result from interactions between microorganisms rather than by alteration of host functions. In this context, bacteriocins are often cited as important effectors of the suspected probiotic effects of lactobacilli in the intestinal tract of man and animals. If successfully extracted and colonized, keratinized squamous epithelium of the mouse stomach. When testing for antagonism, $C$. perfringens, $E$. coli, $S$. aureus, Salmonella sp., Streptococcus mutants and other lactobacilli do not get inhibited.

\section{APPLICATIONS OF BACTERIOCINS}

Some LAB demonstrated antagonism towards pathogenic and spoilage organisms. While bacteriocins are produced by many gram-positive and gram-negative species, those produced by LAB are of particular interest to the food industry because these bacteria are considered safe. Bacterial fermentation of perishable raw materials has been used for centuries to preserve the nutritive value of food and beverages over an extended shelf life [25]. The production of bacteriocins by lactic acid bacteria is advantageous for the survival of the bacteria produced in a competitive ecological niche; thereafter, they could be exploited by the food industry as a tool to control unwanted bacteria naturally and in food quality, which is probably more acceptable to consumers [25]. Among the LAB, a huge diversity of the bacteriocins is produced and some of them are patented for their applications in foods. To date, the only commercially produced bacteriocins are the group of nisins produced by Lactococcus lactis, and pediocin PA-1, produced by Pediococcus acidilactici. The lytic ability of bacteriocins like nisin may be explored in the acceleration of cheddar cheese ripening. Cell lysis of the starter culture is advantageous for improved flavour development [10]. Minimum processed have been refrigerated foods had been gained by consumer acceptance in the last years due to their natural appeal. However, the safety of these foods is of concern is due to the possible presence of non-proteolytic toxic strains of Clostridium botulinum, able to grow at $4^{\circ} \mathrm{C}$, and the postprocessing contamination with psychotropic pathogens, such as Listeria monocyte gene [23]. A pathogenic bacterium, Listeria monocyte gene have been involved in worldwide outbreaks of several foodborne and causes special concern with regard to food safety due to its psychotropic and ubiquitous characteristics. The presence of this pathogen in fermented sausages and in 
vacuum-packaged meat products is of particular interest for food safety, as these two groups of meat are frequently eaten without reheating. This pathogen has been observed which is able to survive at in salt concentration up to $10 \%$ and at lower $\mathrm{pH} 3.6$ in food in the presence of surfactants, sanitisers and after several cycles of freezing and thawing, being a serious risk [23]. The experiment resulted that at $8^{\circ} \mathrm{C}, \mathrm{L}$. monocytogenes was inhibited by bacteriocin of Lactobacillus sakei and the antimicrobial peptide will remain stable during all the experiment (10 days) L. sakei antilisterial activity was partially lost at $15^{\circ} \mathrm{C}$, which is the limitation for the food industry if bacteriocin would be applied as an additional hurdle for the preservation of foods.

\section{MODE OF USES}

There are three or more ways to incorporate bacteriocins into a food to improve its safety. i.e., using a purified/semi-purified bacteriocin preparation as an ingredient in food, by absorbing an ingredient which is previously fermented with a strain produced by bacteriocins, or by using a bacteriocinproducing culture to replace all or part of a starter culture in fermented foods to produce the bacteriocin in situ. Bacteriocins may be incorporated into food in the form of concentrated but not purified preparations using food-quality techniques [16]. When analyzing new candidates, there are many factors that determine their usefulness in food systems. One of the most important criteria is the ability to handle thermal treatment. Thermal processing is used broadly within the food manufacturing process and can have harmful effects on the bio-active capacity of a bacteriocin, potentially supplying it less effective. The physical properties and chemical properties of a food, e.g. pH and fat content, can also play a significant role in the suitability of particular bacteriocins.

Some of the food ingredients may interfere with the bacteriocin's activity. A study was constructed specifies that the use of lactocin 705 to control L. monocytogenes was less effective in the presence of curing ingredients such as sodium chloride, sodium nitrite, ascorbic acid, alginate and sodium lactate. While lactocin 705 appears to be an effective inhibitor of the pathogen, the presence of sodium chloride has replaced bactericidal inhibition by bacteriostatic inhibition. The comparision of nisin and a protective culture against Listeria monocytogenes in tofu, a non-fermented soybean product with a relatively high $\mathrm{pH}$, which may be contaminated during treatment due to collapse or pathogenic bacteria, 
including L. monocytogenes [27]. When nisine was added during tofu production, the results were remarkably better than when it was added as a solution in the end product. The study also showed that the similarity of nisine with mutants resistant to Lactobacillus sakei $\mathrm{Lb} 706$ nisine was more productive in suppressing $\mathrm{L}$ growth. monocytogenes as nisin only. The application of protective cultures alone has not successfully removed Listeria proliferation in low-temperature tofu. To manipulate multiple factors for controlling growth its survival in food, hurdle technology is used [23]. A combination of preservation methods can be worked combined or at least provide greater protection than a single method alone, thus improving the safety and quality of a food. The application of bacteriocins or bacteriocin-producing lactic acid bacteria strains in food has a potential use as part of the hurdle technology, since bacteriocins have shown synergies with other treatments and can be used to improve the safety of food. Though the nature of the Gramnegative cell wall limits the activity of LAB bacteriocins, bacteriocins may be used in mixture with other treatments to increase their effectiveness [23]. A bacteriocin alone in a food is not likely to make sure satisfactory safety. This is of particular significance with consideration to pathogenic bacteria which are gram-negative that are protected by the presence of an outer membrane. When the outer membrane is impaired by agents such as the food-grade chelating agent EDTA, which acts by binding to $\mathrm{Mg}$ ions in lipopolysaccharide; the outer membrane is disrupted, rendering Gramnegatives sensitive to bacteriocins [15, 23]. Bioactive packaging is another potential application in which bacteriocins or production strains can be incorporated into the packaging for contact with food [15]. Obtained good results when packing meat products using a bacteriocin-producer strain of Lactobacillus sakei synergically with modified atmosphere packing. This system combines the preservation function of bacteriocins with typical packaging materials, which protects the food from external contaminants. Refrigerated food spoilage usually begins with growth of microbes on the surface, which reinforces the attractive use of bacteriocins being used in packaging to improve food safety and improve shelf life.

In addition to the difficulty represented by low temperature and vacuum packaging, the use of the bioprotective culture L. curvatus CRL705 as well as its bacteriocins lactocin 705 and AL705 in fresh meat will make sure 
its microbiological safety [22]. One of the concerns regarding the use of bacteriocins is the development of highly tolerant and/or resistant sensitive strains [10, 13]. This selection of bacteriocin-resistant or tolerant strains and variants may create further difficulties in the use of bacteriocins in biopreservation.

\section{RESISTANCE OF BACTERIOCINS}

An important facet to require into thought in relevance the industrial use of bacteriocins is that the tolerance or resistance of sure infective microorganism species that square measure commonly sensitive, such as L. monocytogenes, since it should compromise the medication potency of those compounds [15]. From the sensible prespective, given distinction given mechanics of inhibition and cross-resistance of survivors, it's traditional for he combined use of nisin and one among different bacteriocins would end in a lot of economical inhibition of true bacteria. Bouttefroy and Milliere have combined nisin and curvacitin thirteen to avoid the event of resistant strains of this genus. The employment of strains that turn out multiple bacteriocins can be advantageous to limit the potential emergence of bacteriocin-resistant populations. Resistance will occur naturally and it's been rumored particularly with regards to category IIa bacteriocins like pediocin PA-1 and peritoneum in Y105 among others [25]. Given the way within which bacteriocins area unit seemingly to be employed in food, i.e. collectively of variety hurdles, it's unlikely that the food business can see the emergence of bacteriocinresistant microorganism within the extent to that antibiotic-resistant pathogens have emerged in hospitals. However, the employment of double bacteriocin manufacturing strains would offer a further barrier to make sure that the emergence of resistant populations is even less seemingly. Despite of their limitations, bacteriocins might facilitate to resolve some actual food safety issues. The restriction obligatory on antibiotics use in foods and feeds, and considering the effectiveness of bacteriocins, the existence of viable means that through that they will be incorporated and a consumer's want for minimally processed food, is a wonderful various for its use together with different natural preservatives or agents [25].

\section{CONCLUSION}

In the current period of Bacteriocins, Lactic acid bacteria and antibiotic resistance maybe only the treatment for some clinical cases. Novel applications of LAB and Bacteriocins are steadily increased with the possibility of more interesting roles to be played by the 
agents in future, like in specific site drug delivery and strategies of anti-quorum sensing. A diverse group of bacteriocins are produced from LAB which is responsible for the animus of other gram-positive bacteria. The bacteriocidal activity of pediocin A surrounds a wide range of gram-positive bacteria, whereas the bacteriocidal activities in other bacteriocins like lactacin B and F, Lactocin 27, Helveticin $\mathrm{J}$ are restricted to those species which are closely related to producer strains. Somehow LAB is unique in two types of bacteriocins production, one type it inhibits the classic spectrum of bacteriocidal action which only affects closely related species and the second type which is less common, but they are effective against numerous gram-positive genera. A more focused research study is needed to include in vivo and in vitro analysis, to ensure the safety and effectiveness of lactic acid bacteria and clinical application of their bacteriocins.

\section{REFERENCE}

[1] Adams MR, Moss MO. Fermented and microbial foods. In Food microbiology 2000 May 4 (pg. 311-369).

[2] Todorov SD. Bacteriocins from Lactobacillus plantarum production, genetic organization and mode of action: produção, organização genética e modo de ação. Brazilian journal of microbiology. 2009 Jun; 40 (2): 209-21.

[3] Hati S, Mandal S, Prajapati JB. Novel starters for value added fermented dairy products. Current Research in Nutrition and Food Science Journal. 2013 Aug 27; 1(1): 83-91.

[4] Mokoena MP. Lactic acid bacteria and their bacteriocins: classification, biosynthesis and applications against uropathogens: a mini-review. Molecules. 2017 Aug; 22(8): 1255.

[5] Perez RH, Zendo T, Sonomoto K. Novel bacteriocins from lactic acid bacteria (LAB): various structures and applications. Microbial cell factories. 2014 Aug; 13(1): 1-3

[6] Riley MA, Wertz JE. Bacteriocins: evolution, ecology, and application. Annual Reviews in Microbiology. 2002 Oct; 56(1): 117-37.

[7] De Martinis EC, Públio MR, Santarosa PR, Freitas FZ. Antilisterial activity of lactic acid bacteria isolated from vacuum-packaged Brazilian meat and meat products. Brazilian Journal of Microbiology. 2001 Mar; 32(1): 32-7.

[8] Parada JL, Gaón D, Chekherdemian M. Enfoque bioquímico y genético de la resistencia a los antibióticos. Ars Curandi. 1980; 4: 240-5.

[9] Klaenhammer TR. Genetics of bacteriocins produced by lactic acid 
bacteria. FEMS microbiology reviews. 1993 Sep 1; 12(1-3):39-85.

[10] Deegan LH, Cotter PD, Hill C, Ross P. Bacteriocins: biological tools for biopreservation and shelf-life extension. International dairy journal. 2006 Sep 1; 16(9): 1058-71.

[11] McAuliffe O, Ross RP, Hill C. Lantibiotics: structure, biosynthesis and mode of action. FEMS microbiology reviews. 2001 May 1; 25(3): 285-308.

[12] Van Belkum MJ, Worobo RW, Stiles ME. Double-glycine-type leader peptides direct secretion of bacteriocins by $\mathrm{ABC}$ transporters: colicin $\mathrm{V}$ secretion in Lactococcus lactis. Molecular microbiology. 1997 Mar; 23(6): 1293-301.

[13] Chung KT, Dickson JS, Crouse JD. Effects of nisin on growth of bacteria attached to meat. Applied and Environmental Microbiology. 1989 Jun 1; 55(6): 1329-33.

[14] Yang R, Johnson MC, Ray BI. Novel method to extract large amounts of bacteriocins from lactic acid bacteria. Applied and environmental microbiology. 1992 Oct 1; 58(10): 3355-9

[15] De Martinis EC, Públio MR, Santarosa PR, Freitas FZ. Antilisterial activity of lactic acid bacteria isolated from vacuum-packaged Brazilian meat and meat products. Brazilian Journal of Microbiology. 2001 Mar; 32(1): 32-7.

[16] McCORMICK EL, Savage DC. Characterization of Lactobacillus sp. strain 100-37 from the murine gastrointestinal tract: ecology, plasmid content, and antagonistic activity toward Clostridium ramosum $\mathrm{H} 1$. Applied and environmental microbiology. 1983 Nov 1; 46(5): 1103-12.

[17] Zacharof MP, Lovitt RW. Bacteriocins produced by lactic acid bacteria a review article. APCBEE Procedia 2: 50-56.

[18] Liu M, Sun Q, Liu A. Composition of lactic acid bacteria in dairy products and their effect on tourism development of inner Mongolia. The Annals of the University Dunarea de Jos of Galati. Fascicle VI-Food Technology. 2016 Jun 27; 40(1): 67-77

[19] Guinane CM, Cotter PD, Hill C, Ross RP. Microbial solutions to microbial problems; lactococcal bacteriocins for the control of undesirable biota in food. Journal of Applied Microbiology. 2005 Jun; 98(6): 1316-25.

[20] Bierbaum G, Sahl HG. Lantibiotics: mode of action, biosynthesis and bioengineering. Current pharmaceutical biotechnology. 2009 Jan 1; 10(1):2-18.

[21] Upreti GC, Hinsdill RD. Isolation and characterization of a bacteriocin from a 
homo fermentative Lactobacillus.

Antimicrobial Agents and

Chemotherapy. 1973 Oct 1; 4(4):487-

94.

[22] Castellano P, Vignolo G. Inhibition of Listeria innocua and Brochothrix thermosphacta in vacuum-packaged meat by addition of bacteriocinogenic Lactobacillus curvatus CRL705 and its bacteriocins. Letters in Applied Microbiology. 2006 Aug; 43(2): 194-9.

[23] Deegan LH, Cotter PD, Hill C, Ross P. Bacteriocins: biological tools for biopreservation and shelf-life extension. International dairy journal. 2006 Sep 1; 16(9): 1058-71

[24] Dziva F, Stevens MP. Colibacillosis in poultry: unravelling the molecular basis of virulence of avian pathogenic Escherichia coli in their natural hosts. Avian Pathology. 2008 Aug 1; 37(4): 355-66.

[25] Torshizi MA, Rahimi SH, Mojgani N, Esmaeilkhanian S, Grimes JL. Screening of indigenous strains of lactic acid bacteria for development of a probiotic for poultry. AsianAustralasian Journal of Animal Sciences. 2008 Sep 4; 21(10): $1495-$ 500.

[26] Parada JL, Caron CR, Medeiros AB, Soccol CR. Bacteriocins from lactic acid bacteria: purification, properties and use as biopreservatives. Brazilian archives of Biology and Technology. 2007 May; 50(3): 512-42.

[27] Molina G, Pelissari FM, Pessoa MG, Pastore GM. Bioactive compounds obtained through biotechnology. Biotechnology of Bioactive Compounds: Sources and Applications. 2015 Jan 22: 433. 